Article

\title{
Architectured Cu-TNTZ Bilayered Coatings Showing Bacterial Inactivation under Indoor Light and Controllable Copper Release: Effect of the Microstructure on Copper Diffusion
}

\author{
Akram Alhussein ${ }^{1, *} \mathbb{C}$, Sofiane Achache ${ }^{1}$, Regis Deturche ${ }^{2}$ and Sami Rtimi ${ }^{3, *(1)}$ \\ 1 ICD-LASMIS, Université de Technologie de Troyes, Antenne de Nogent, Pôle Technologique Sud \\ Champagne, 52800 Nogent, France; sofiane.achache@utt.fr \\ 2 ICD-L2N, Université de Technologie de Troyes, 12 Rue Marie Curie, 10010 Troyes, France; \\ regis.deturche@utt.fr \\ 3 Ecole Polytechnique Fédérale de Lausanne, EPFL-STI-IMX-LTP, 1015 Lausanne, Switzerland \\ * Correspondence: akram.alhussein@utt.fr (A.A.); rtimi.sami@gmail.com (S.R.); Tel.: +33-35-1591174 (A.A.); \\ +41-21-6936150 (S.R.); Fax: +33-32-5717676 (A.A.)
}

Received: 16 May 2020; Accepted: 15 June 2020; Published: 19 June 2020

check for updates

\begin{abstract}
A Ti-23Nb-0.7Ta-2Zr-1.2O alloy (at \%), called "gum metal", was deposited by direct-current magnetron sputtering (DCMS) on an under layer of copper. By varying the working pressure during the deposition, columnar TNTZ (Ti-Nb-Ta-Zr) nanoarchitectures were obtained. At low working pressures, the upper layer was dense with a coarse surface $\left(R_{\mathrm{a}}=12 \mathrm{~nm}\right)$ with a maximum height of $163 \mathrm{~nm}$; however, the other samples prepared at high working pressures showed columnar architectures with voids and an average roughness of $4 \mathrm{~nm}$. The prepared coatings were characterized using atomic force microscopy (AFM) for surface topography, energy dispersive X-ray spectroscopy (EDX) for atomic mapping, scanning electron microscopy (SEM) for cross-section imaging, contact angle measurements for hydrophilic/hydrophobic balance of the prepared surfaces, and X-ray diffraction $(\mathrm{XRD})$ for the crystallographic structures of the prepared coatings. The morphology and the density of the prepared coatings were seen to influence the hydrophilic properties of the surface. The antibacterial activity of the prepared coatings was tested in the dark and under low-intensity indoor light. Bacterial inactivation was seen to happen in the dark from samples presenting columnar nanoarchitectures. This was attributed to the diffusion of copper ions from the under layer. To verify the copper release from the prepared samples, an inductively coupled plasma mass spectrometer (ICP-MS) was used. Additionally, the atomic depth profiling of the elements was carried out by X-ray photoelectron spectroscopy (XPS) for the as-prepared samples and for the samples used for bacterial inactivation. The low amount of copper in the bulk of the TNTZ upper layer justifies its diffusion to the surface. Recycling of the antibacterial activity was also investigated and revealed a stable activity over cycles.
\end{abstract}

Keywords: titanium-based thin films; copper; magnetron sputtering; super-elastic coatings; E. coli inactivation

\section{Introduction}

Thin films of titanium alloys are highly used in biomedical fields due to their lightness, low elasticity modulus, good mechanical strength, biocompatibility, and anticorrosion behavior [1,2]. These properties depend on the film elemental composition [3]. The favorable phase of $\beta$-type Ti-based thin films presents a body-centered cubic (bcc) structure, low density, and Young's modulus. $\beta$-type Ti-based 
thin films containing nontoxic elements and non-allergic properties have been largely developed during these last years. The enhancement of their mechanical properties and super-elastic performance is one of the most important issues [2-5]. After developing $\mathrm{Ti}-\mathrm{Nb}-\mathrm{Zr}-\mathrm{Ta}$ (TNTZ) bulk alloys, in particular the multifunctional Ti-23Nb-0.7Ta-2Zr-1.2O alloy (at \%), called "gum metal", it has been shown that these alloys can be used in the form of super-elastic thin films. These films present an important potential for medical applications and/or microactuation, such as for stents for neurovascular blood vessels or membrane-based micropumps [6-9].

In the present work, two superposed layers, namely gum metal (GM) and copper thin films, were deposited on glass substrates by direct-current magnetron sputtering (DCMS) of an alloying target $\mathrm{Ti}-23 \mathrm{Nb}-0.7 \mathrm{Ta}-2 \mathrm{Zr}$ (at \%) and a pure $\mathrm{Cu}$ target. In previous studies [10-12], we reported the beneficial effect of $\mathrm{Cu}$ ions on enhancing the catalytic/photocatalytic bacteria inactivation when added to a gum metal thin film (GMTF). Many copper-based coatings such as $\mathrm{TiO}_{2}-\mathrm{Cu}, \mathrm{Cu}, \mathrm{Ti}, \mathrm{Nb}$, and their oxides were developed and investigated, mainly for their antibacterial properties. In our previous studies [13-15], we reported the mechanical properties of a superelastic Ti-based GMTF showing increased bacterial inactivation under light concomitant to a biocompatible property in darkness [16,17]. We also showed the effect of copper content on the structure, morphology, and mechanical properties of GMTF [18]. We also showed that the TNTZ-Cu 8.3 at \% Cu sample with the highest roughness (RMS value of $20.1 \mathrm{~nm}$ ) led to the highest bactericidal activity.

The present study focuses on the bacterial inactivation of sputtered GMTF films deposited with different pressure values on copper diffusion to the surface mediating the bacterial inactivation. The application of different pressure values in this study was designed to lead to different layer densities and microarchitectures (disordered tubes or arranged columns). The influence of the morphology of the TNTZ upper layer allowing copper diffusion is investigated in the dark and under indoor visible-light irradiation. The interfacial interaction, potential, and $\mathrm{pH}$ between the bacterial cells on the sputtered films are reported within the disinfection time on these innovative bilayered $\mathrm{Cu}$-TNTZ coatings. The sustainable use (reusability) of the sputtered samples was also studied, showing a long operational lifetime of the gradual release of copper from the sputtered films. The reported thin films show a potential application in biomedical settings, leading to self-sterilization of surfaces without harmful side-effects related to the excess of toxic ions, especially in circumstances of increased infection risks in hospitals. The novelty of this work resides in the preparation of a coating allowing fast bacterial inactivation with reduced ion release.

\section{Experimental Details}

\subsection{Deposition Procedures of the Nanoarchitected Films of $\mathrm{Cu}$ and TNTZ}

Bilayer films composed of $\mathrm{Cu}$ and gum metal (TNTZ) were consecutively deposited on glass substrates and silicon wafers ( 100$)$ at floating temperature by DCMS from two targets ( $99.9 \%$ purity): pure $\mathrm{Cu}$ and $\mathrm{Ti}-23 \mathrm{Nb}-0.7 \mathrm{Ta}-2 \mathrm{Zr}$ (at \%), respectively. Two similar magnetrons joined to rectangular targets $200 \times 100 \times 6 \mathrm{~mm}^{3}$ in size were used. The chamber was evacuated down to a pressure of $4 \times 10^{-4} \mathrm{~Pa}$. The target-to-sample distance was kept constant at $8 \mathrm{~cm}$. After initial optimization, the first layer of copper was sputtered for $20 \mathrm{~s}$ and then the second layer of TNTZ was carried out for $40 \mathrm{~s}$. The thickness of the $\mathrm{Cu}$-TNTZ bilayer films was approximately $1 \mu \mathrm{m}$. The sample holder rotation speed was set to $12 \mathrm{rpm}$. The working pressure was varied between 0.15 and $2 \mathrm{~Pa}$, corresponding to the argon flow rate of 15-140 sccm. Figure 1 illustrates the setup used for the deposition, and Table 1 illustrates the deposition parameters of $\mathrm{Cu}$-TNTZ bilayered thin films. 


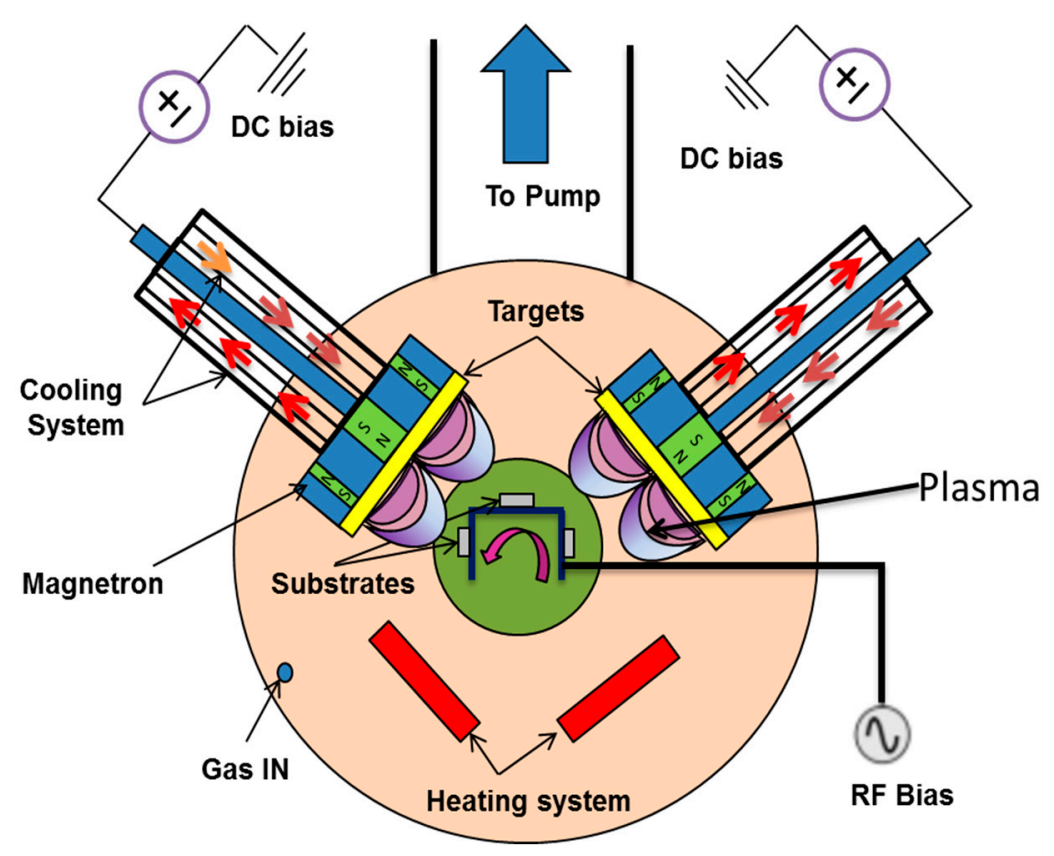

Figure 1. Schematic view of the setup used for the bilayered film deposition.

Table 1. Elaboration conditions of $\mathrm{Cu}-\mathrm{TNTZ}(\mathrm{Ti}-\mathrm{Nb}-\mathrm{Ta}-\mathrm{Zr}$ ) bilayered thin films.

\begin{tabular}{|c|c|c|c|c|}
\hline \multirow{2}{*}{ Sample } & \multicolumn{2}{|c|}{ Cu Under Layer } & \multicolumn{2}{|c|}{ TNTZ Upper Layer } \\
\hline & $\begin{array}{c}\text { Argon Flow Rate } \\
\text { (sccm) }\end{array}$ & $\begin{array}{l}\text { Working Pressure } \\
\text { (Pa) }\end{array}$ & $\begin{array}{c}\text { Argon Flow Rate } \\
\text { (sccm) }\end{array}$ & $\begin{array}{l}\text { Working Pressure } \\
\text { (Pa) }\end{array}$ \\
\hline I & & & 15 & 0.15 \\
\hline II & 15 & 0.15 & 50 & 0.5 \\
\hline III & & & 90 & 1 \\
\hline IV & & & 140 & 2 \\
\hline
\end{tabular}

2.2. Physical and Chemical Characterization of the Sputtered Samples by Energy Dispersive X-Ray Spectroscopy (EDX), SEM, Atomic Force Microscopy (AFM), and XRD

The elemental compositions of the TNTZ films were obtained by energy dispersive X-ray spectroscopy (EDX) using Quantax Esprit software version 2.0 (Bruker Nano GmbH, Berlin, Germany). The bilayer $\mathrm{Cu}$-TNZT cross-section images were observed by a Hitachi SU8030 scanning electron microscope (SEM) (Tokyo, Japan). For each sample, the measurements were carried out on multiple zones of the sample and showed a significant homogeneity. The elements spectra were acquired from SEM images applying an accelerating voltage of $10 \mathrm{kV}$ and a pressure vacuum of $10^{-4} \mathrm{~Pa}$. The surface roughness and the topography of the thin films were obtained by atomic force microscopy (Agilent Technologies 5100 AFM, Stevens Creek, CA, USA). The AFM 3D-images were acquired in noncontact mode at the resonance frequency of the ultrasharp silicon tip and with the set point fixed at $10 \%$ of the maximum amplitude. The AFM images of $256 \times 256$ pixels were obtained with a scanning speed of $0.4 \mathrm{~s} /$ line (acquisition of 256 points/line).

The microstructure of the thin films was analyzed by X-ray diffraction (XRD) using a Bruker D8 Advance diffractometer ( $\mathrm{CuK} \alpha$ radiation line, Karlsruhe, Germany). The hydrophilic/hydrophobic properties of the sputtered films were evaluated by contact angle measurements based on the static sessile drop method. Water droplets $(3 \mathrm{~mL})$ were dropped on the films and the contact angles were measured. The droplet profiles were acquired using a camera (SCA software, version 4.5.14) for OCA and PCA Drpo6) aligned with the sample and a backlighting source. For this study, Si wafers were 
used in order to observe the film morphology and to quantify the film elemental composition. Glass substrates (Leica, Germany) were used to perform the other characterizations and antibacterial tests.

\subsection{Bacterial Adhesion to the Coating Surface, Bacterial Inactivation Testing, and the Sustainability of the Coatings}

Escherichia coli (E. coli K12) used in this study was obtained from DSMZ (Braunschweig, Germany). The bacterial adhesion to the TNTZ and Cu-TNTZ was carried out by immersing the samples into $5 \mathrm{~mL}$ E. coli suspension (initial concentration of $2.2 \times 10^{6} \mathrm{CFU} / \mathrm{mL}$ ). The tube was then horizontally shacked gently for $4 \mathrm{~h}$ in an incubator at $37^{\circ} \mathrm{C}$ in the dark $[19,20]$. The non-adhered and the weakly adhered bacteria to the surface were washed out with a phosphate buffer solution (pH 7.2). The attached cells were then detached from the surface using ultrasonication ( $50 \mathrm{~W}, \mathrm{CA}, \mathrm{USA}$ ) for $15 \mathrm{~min}$, and the number of viable cells was determined by plate-count agar.

For the bacteria inactivation testing, aliquots of $100 \mu \mathrm{L}$ (initial concentration of $4.2 \times 10^{6} \mathrm{CFU} / \mathrm{mL}$ ) in saline solution $(\mathrm{NaCl} / \mathrm{KCl}, 8 / 0.8 \mathrm{~g} / \mathrm{L}$ at $\mathrm{pH}$ 7.2) were placed on the samples that were placed in glass petri dishes at room temperature. Then, the samples were transferred into a sterile tube containing saline solution and subsequently mixed thoroughly using a Vortex (Staufen, Germany) for 2 min. Serial dilutions were made. A sample of $100 \mu \mathrm{L}$ from each dilution was pipetted onto a nutrient agar plate (Zurich, Switzerland) and spread over the surface of the plate. Agar plates were incubated lid down for $24 \mathrm{~h}$ at $37^{\circ} \mathrm{C}$ before counting. Three independent assays were done for each sample. The statistical analysis of the results was performed for the CFU values calculating the standard deviation $(n=5 \%)$. Irradiation of the samples was carried out under tubular Osram Lumilux (Munich, Germany) 18W/827 light $\left(4.2 \mathrm{~mW} / \mathrm{cm}^{2}\right)$ emitting in the range of 360-700 $\mathrm{nm}$.

Bacterial inactivation recycling was carried out under light and in the dark. After each cycle, the sample was washed three times with distilled water and dried between each washing. All the bacterial inactivation tests were carried out in triplicate.

\subsection{Copper Release and Atomic Etching of the Architectured Samples}

A Finnigan ${ }^{\mathrm{TM}}$ inductively coupled plasma mass spectrometer (ICP-MS) (Zug, Switzerland) was used to detect the $\mathrm{Cu}$ released during the bacterial loss of viability runs. In addition, to test the long-term stability, the coated specimens were immersed in $20 \mathrm{ml}$ PBS and kept at $37^{\circ} \mathrm{C}$ for $1,2,3$, and 5 days. This instrument was equipped with a double-focusing reverse geometry mass spectrometer having an extremely low background signal and high ion-transmission coefficient with a detection limit of $0.2 \mathrm{ppb}$. Each specimen was tested in triplicate.

X-ray photoelectron spectroscopy (XPS) analysis of the films was determined using an AXIS Nova photoelectron spectrometer (Kratos Analytical, Manchester, UK) provided with a monochromatic AlK $\alpha(h v=1486.6 \mathrm{eV})$ anode operated with a voltage of $15 \mathrm{kV}$ and a power of $400 \mathrm{~W}$. The carbon C1s line position at $284.6 \mathrm{eV}$ was used as the reference to correct for charging effects. The base pressure below $5 \times 10^{-7}$ Pa was maintained during the measurements. No argon sputtering was considered to clean the specimen surfaces. The surface atomic concentration percentage for each element was determined from peak areas using the known sensitivity factors for each element on the coated surfaces. The etching of the film surfaces was carried out by Ar ions of $5 \mathrm{kV}$ reaching a depth of $\sim 50 \mathrm{~nm}$ ( 250 layers). 


\section{Results and Discussion}

3.1. Elemental Composition, Morphology, and Topography of Cu-TNTZ Thin Films Deposited under Different Pressures

The elemental composition of the TNTZ films deposited on a copper layer was determined by EDX. The films were chemically homogeneous and composed similarly of the TNTZ target's elements: Ti-23Nb-0.7Ta-2Zr (at \%). Figure 2 shows fractured cross-section SEM images of different Cu-TNTZ bilayered samples sputtered under different working pressures.
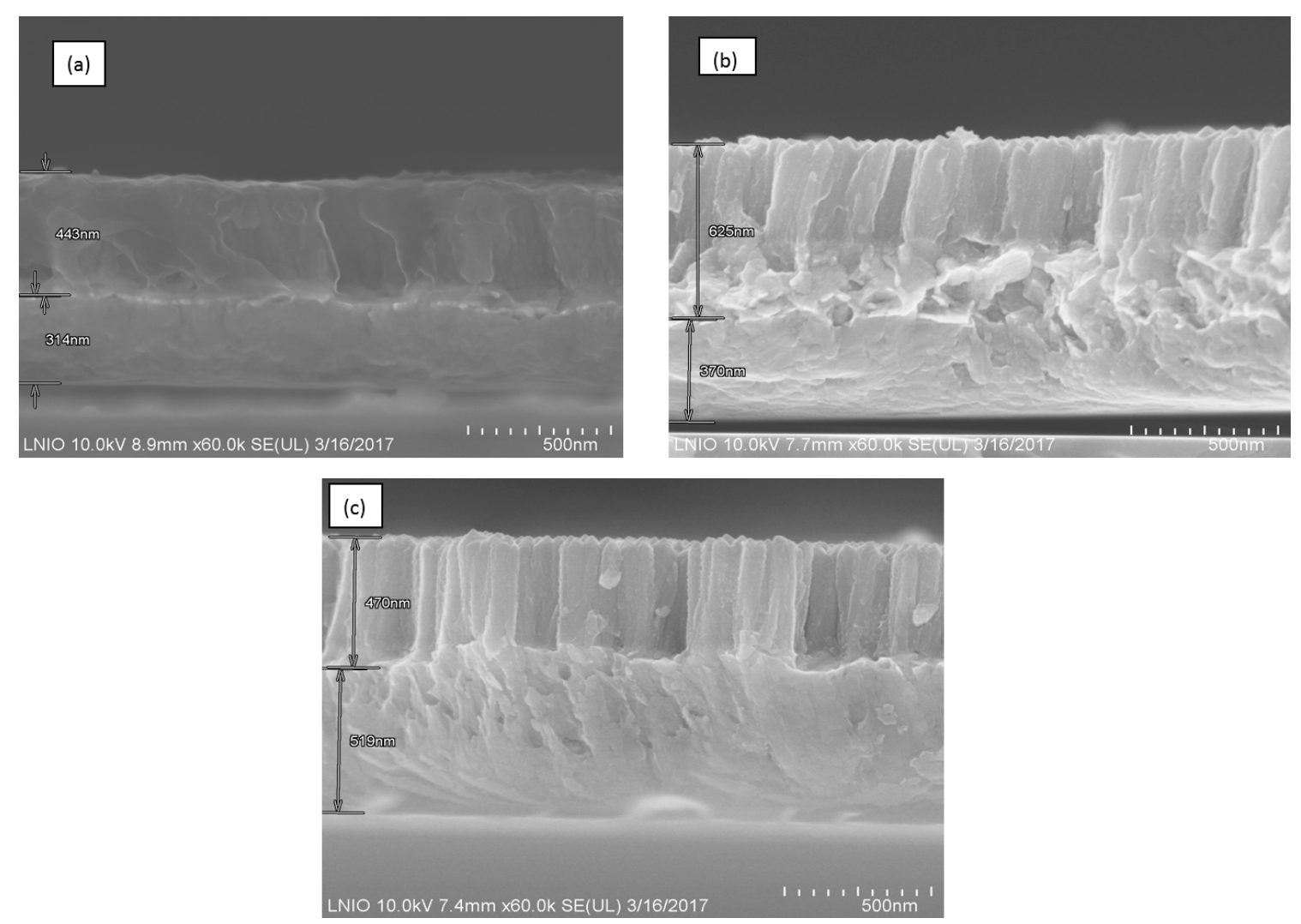

Figure 2. Cross-section SEM images of architectured $\mathrm{Cu}-\mathrm{TNTZ}$ films with different morphologies sputtered at different pressures: (a) $\mathrm{I}-0.15 \mathrm{~Pa}$, (b) II-0.50 Pa, and (c) III $-1 \mathrm{~Pa}$.

A dense layer of $\mathrm{Cu}$ was first deposited under a low constant pressure of $0.15 \mathrm{~Pa}$, then an upper layer of TNTZ was sputtered under different deposition pressures. It is readily seen that by increasing the deposition pressure from 0.15 to $2 \mathrm{~Pa}$, the morphology of the TNTZ films changes. Under low pressures, dense TNTZ upper films were obtained. However, when increasing the deposition pressure, columnar structures were achieved. This structural shift was attributed to the loss of adatom energy and surface mobility because of the collision with argon ions in the plasma phase.

Figure 3 shows the topography of the samples using atomic force microscopy (AFM). The 3D and 2D surface mappings of the TNTZ films (Figure 3) show that the growth of films forms hills and valleys. Except for Sample I, the roughness average of all other Cu-TNTZ bilayer samples is $5 \mathrm{~nm}$. Sample I has the coarsest surface $\left(R_{\mathrm{a}}=12 \mathrm{~nm}\right)$ with a maximum height of $155 \mathrm{~nm}$. 

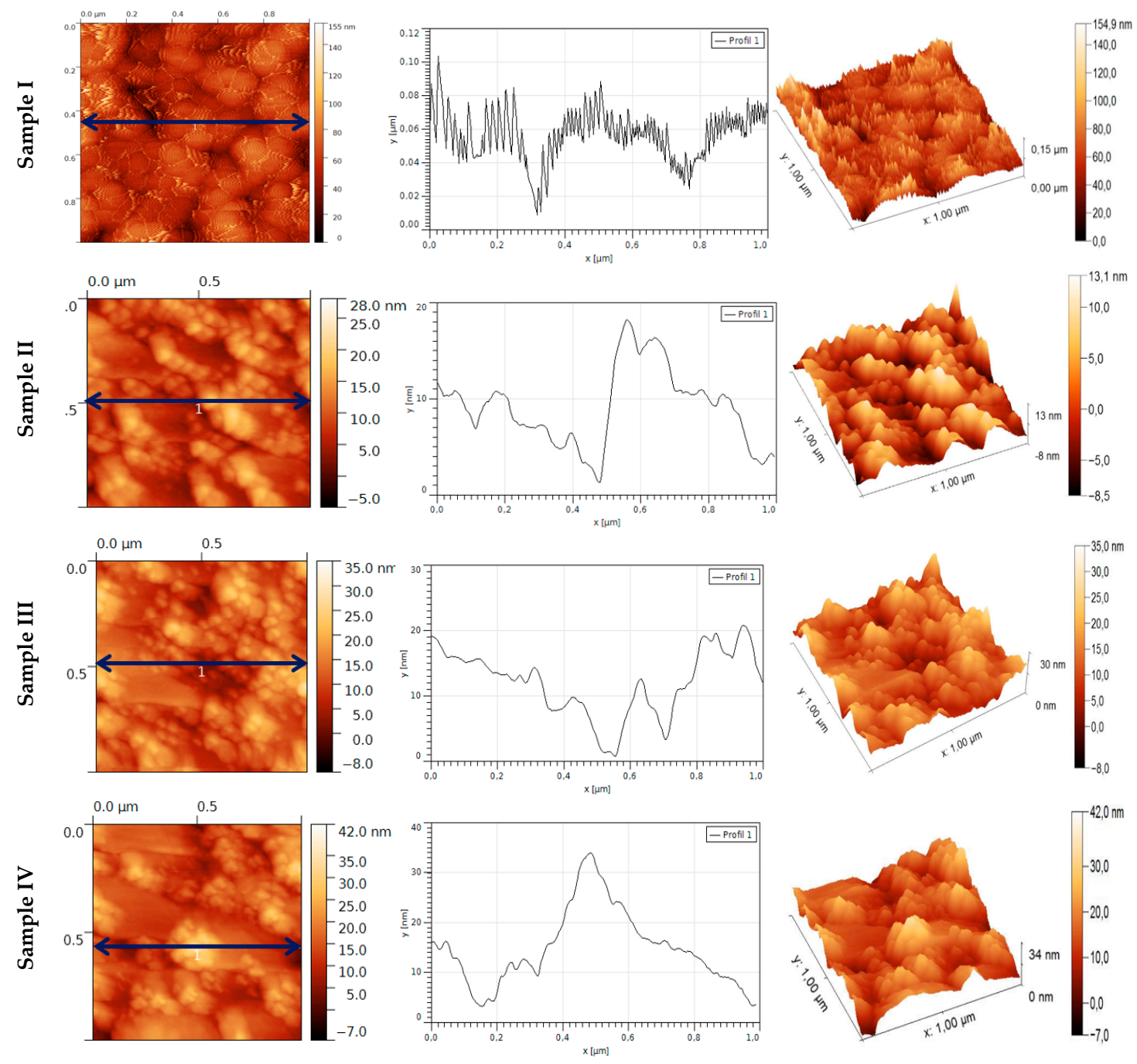

Figure 3. 2D and 3D atomic force microscopy (AFM) of TNTZ thin films sputtered under different pressure conditions. For more details, please see Table 1.

\subsection{Crystalline Structure and Hydrophobic/Hydrophilic Properties of the TNTZ Films}

Figure 4 shows the XRD patterns of the TNTZ films deposited on a copper under layer at different deposition pressures. It is readily seen from Figure 4 that the TNTZ films present a $\beta$-metastable phase. Similar results were observed in our previous study [13]. Furthermore, the crystallinity of TNTZ films decreases with the increase of deposition pressure. The TNTZ film deposited at 2 Pa shows a low-intensity single peak, while others deposited at lower pressures exhibit sharper peaks. Similar trends were observed in our previous study [13]. This can be attributed to the decrease of a mean free path leading to the lower adatom surface mobility. Thus, the adatoms cannot migrate for a larger distance, promoting the formation of fine grains.

The presence of peaks related to the $\mathrm{Cu}$ underlayer is due to the interaction of $\mathrm{X}$-rays with both layers of $\mathrm{Cu}$ and TNTZ. The penetration of $X$-rays within the material is estimated to be $\sim 1 \mu \mathrm{m}$; thus, crystalline phases of both layers show up on the diffractogram [21]. The increase of copper peak intensity with the decrease of deposition pressure could be explained by the decrease of the thickness of the upper TNTZ layer. It is obvious that the decrease of deposition pressure in a sputtering process leads to a decrease of film thickness. Therefore, the diffraction peaks attributed to the copper layer are more remarkable at lower deposition pressures. 


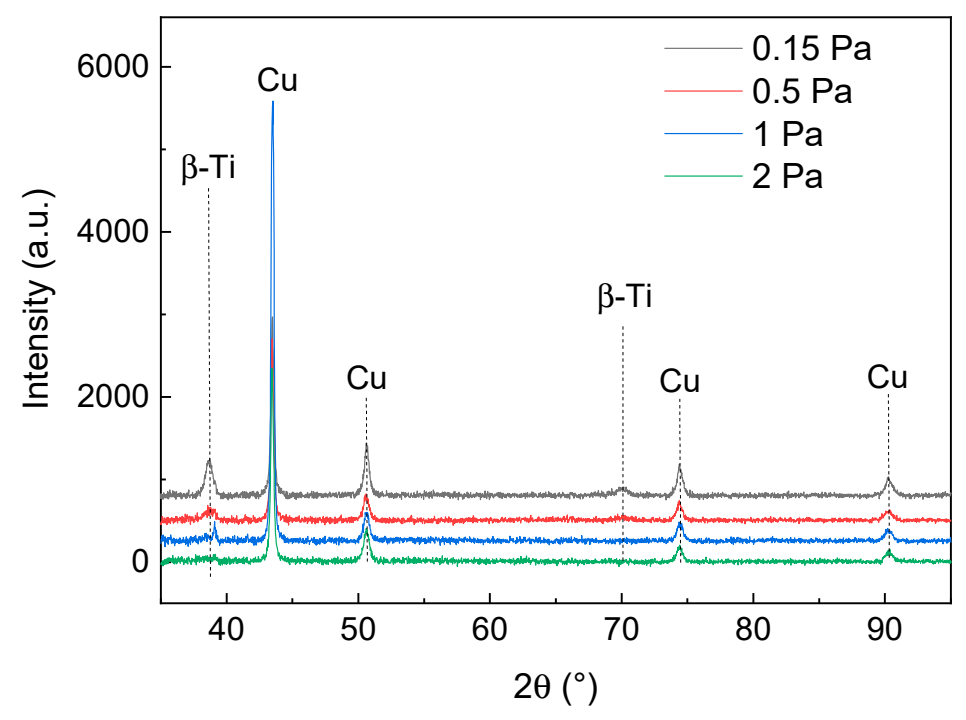

Figure 4. X-ray diffraction (XRD) of architectured $\mathrm{Cu}-\mathrm{TNTZ}$ samples sputtered at different pressures. JCPDS 00-004-0836 and JCPDS 00-044-1288 were used for $\mathrm{Cu}$ and $\beta$-Ti, respectively.

The hydrophilic/hydrophobic properties of the architectured $\mathrm{Cu}$-TNTZ films were evaluated via the contact angles between the films deposited on glass substrates and the water droplets. Water droplets of $3 \mu \mathrm{L}$ in volume fallen on the film surfaces were measured, as shown in Figure 5. The contact angles varied between $81^{\circ}$ and $102^{\circ}$. The roughness, the morphology, and the density of film (as previously shown in Figures 2 and 3) influenced the hydrophilic properties of the surface. The denser and coarser the film was (Sample I, Figures 2 and 3), the lower the contact angle was $\left(81^{\circ}\right)$. For the other films deposited under higher pressures (in the range of 1-2 Pa), the samples exhibited contact angles of $100^{\circ}-102^{\circ}$. As is shown in Figures 2 and 3, these latter films showed columnar architectures and low roughness. The film prepared at $0.5 \mathrm{~Pa}$ showed a contact angle value of $92^{\circ}$.
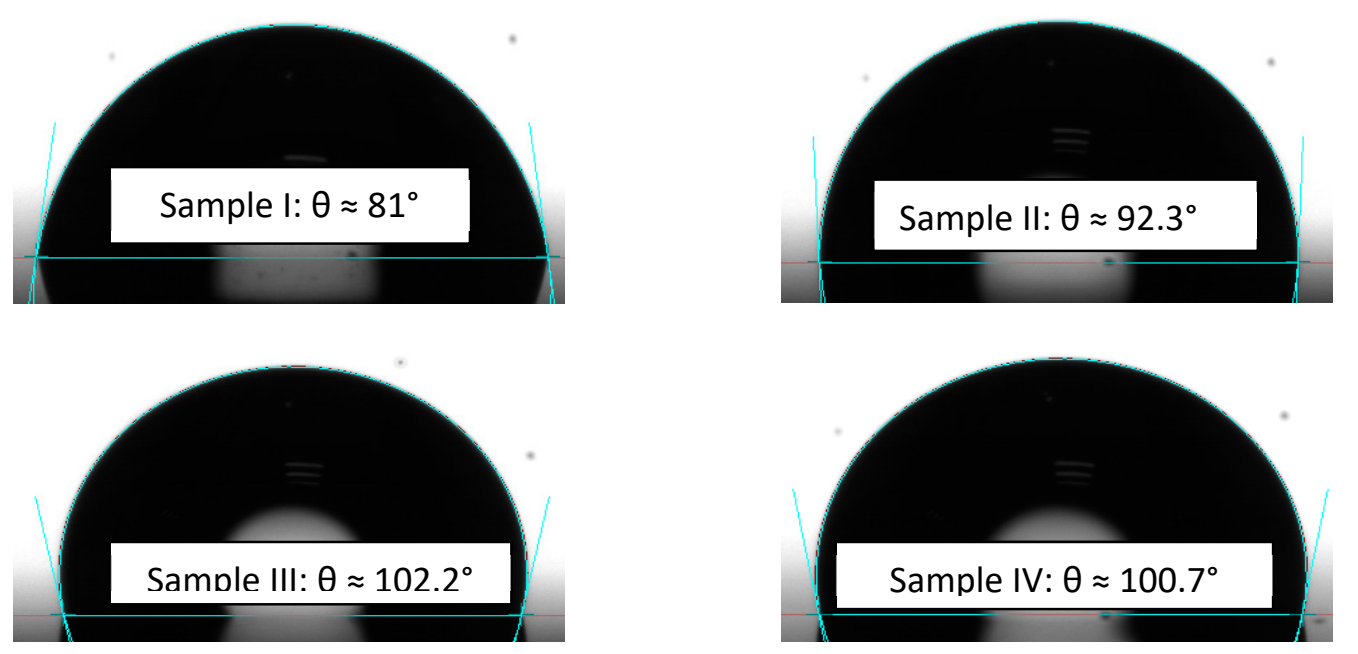

Figure 5. Contact angles between drops of water and $\mathrm{Cu}-\mathrm{TNTZ}$ bilayer films.

\subsection{Bacterial Adhesion and Inactivation, and the Atomic Depth Profiling before and after Bacterial Inactivation}

Bacterial adhesion at the interface of the TNTZ-sputtered films with different architectures was investigated. The TNTZ films sputtered at the different conditions described in Table 1, without the copper underlayer, were used to investigate the influence of the interface topography/microstructure on the E. coli adhesion. The TNTZ-presenting dense/coarse architecture as shown in Supplementary 
Figure S1a exhibited low bacterial adhesion (1.4 $\left.\log _{10} \mathrm{CFU}\right)$ compared to samples showing columnar-shaped microstructures (Figure S1b,c), allowing 2.2 to $2.6 \log _{10} \mathrm{CFU}$ adhesion in the dark. The difference between the samples presenting columnar architectures was not significant in the triplicate experiment carried out. This can be attributed to the hills and valleys at the interface, allowing a larger contact surface with bacteria [22]. Figure 6 shows the possible bacterial interaction with the two different microstructures of sputtered TNTZ thin films. The dense surface presents low contact points with bacteria, leading to the low adhesion ability compared to the columnar counterparts. It is worth mentioning that the chemistry of the surface and its charge may strongly affect the ability of a thin film to adhere to bacteria. Recently, bacterial adhesion to biotic and abiotic surfaces has been investigated in detail [23].

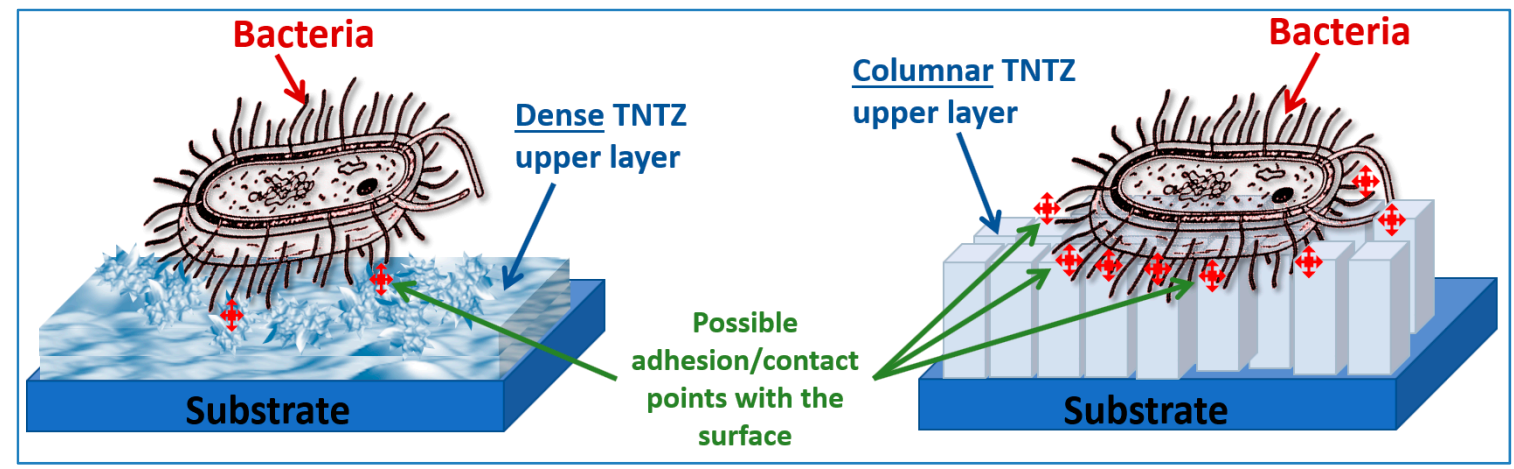

Figure 6. Simplified understanding of the bacterial adhesion to nanoarchitectured surfaces.

Under light, TNTZ films did not exhibit higher bacterial inactivation values compared to their performance in the dark (bacterial adhesion). Under light, dense TNTZ showed 1 log reduction against $1.8 \mathrm{log}$ reduction for columnar TNTZ. This may be due to the oxidation of the forming species at the interface with bacteria forming metal oxides. Under light, these latter oxides generate reactive oxygen species able to inactivate bacteria at their interface. Detailed investigation of this aspect should be carried out to better understand the mechanism of bacterial inactivation under low-intensity indoor light.

Figure 7 shows the bacterial inactivation kinetics on Samples I, II, and III under low-intensity indoor light and in the dark. E. coli inactivation (6 log reduction) was seen to happen within $60 \mathrm{~min}$ on Samples II and III. Sample I showed $3 \log$ bacterial reduction within $300 \mathrm{~min}$ under light $\left(4.2 \mathrm{~mW} / \mathrm{cm}^{2}\right)$.

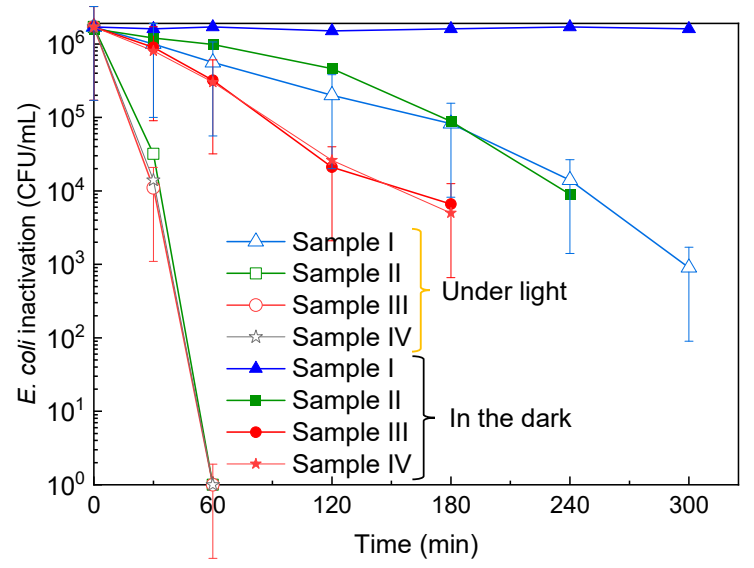

Figure 7. E. coli inactivation on bilayered samples under indoor light and in the dark.

This justifies the semiconductor behavior at the interface of Samples I, II, III, and IV, and the accelerated bacterial inactivation under light is photocatalytic. In the dark, Samples II, III, and 
IV showed $4 \log$ bacterial reduction within 180-240 min. This suggests the existence of toxic ions on the surfaces leading to bacterial inactivation in the dark. Sample I shows that the compact upper layer did not show bacterial reduction in the dark. Therefore, the columnar nanoarchitectures of Samples II, III, and IV allowed the diffusion of copper ions reaching the surface and enhanced the bacterial inactivation in the dark.

Surface atomic percentages of elements as a function of the depth of the sputtered film were also investigated. As Samples II and III showed the fastest bacterial inactivation, we chose to carry the depth profiling on Sample II. However, it is worth mentioning that Samples III and IV exhibited higher copper content on their surfaces than Sample II. Copper ions were not detected at the surface of Sample I, which means that the copper diffusion was blocked by the dense TNTZ upper layer. Figure 8 shows the depth profiling of Sample II. Copper ions encountered at the coating interface were seen to enhance the bacterial inactivation under light and, more importantly, in the dark. It has been recently reported that sputtered films with $\mathrm{Cu}$ in ppm concentrations led to an acceleration of the bacterial inactivation [24].
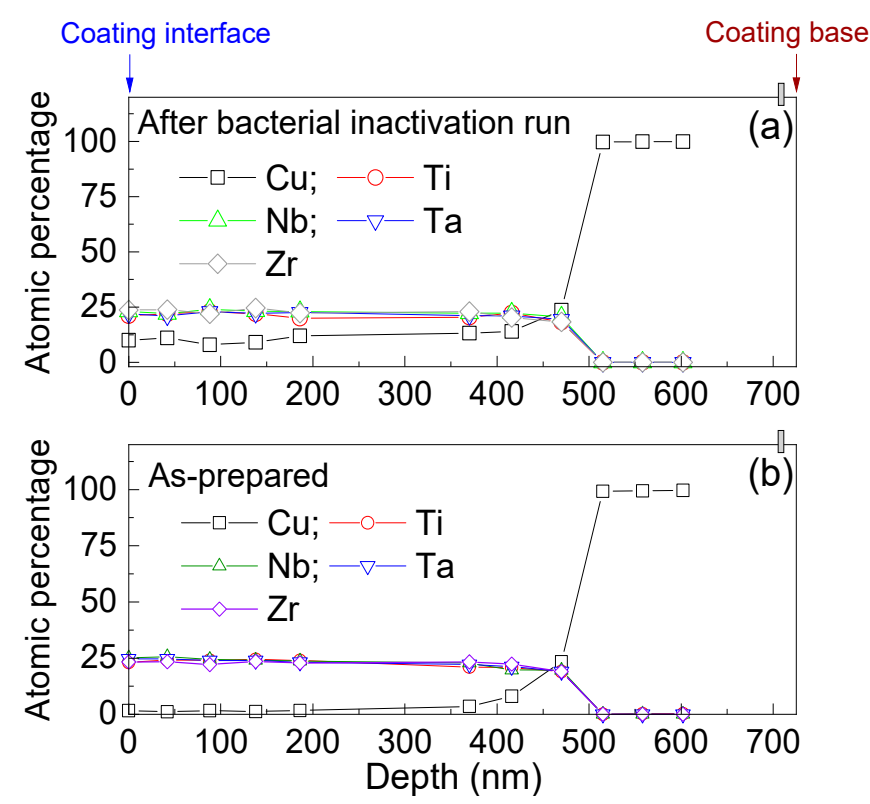

Figure 8. Depth profiling atom distribution in the sputtered layers of Sample II: evidence for copper diffusion in: (a) sample used for bacterial inactivation with respect to (b) an as-prepared sample.

\subsection{Recycling and Ion Release during Bacterial Inaction}

Bacterial inactivation recycling was carried out to test the stability of the prepared antibacterial coatings. Figure 9 shows the recycling of Samples II and III under light and in the dark. It is readily seen from Figure 9 that Samples II and III did not show a significant loss of their activities in up to five washing cycles. Coatings prepared by magnetron sputtering present high adhesivity, uniform distribution on the substrate, and controllable nanoarchitecture [25-27]. This allows their practical application in the biomedical field, environmental remediation, and smart surfaces $[28,29]$. 

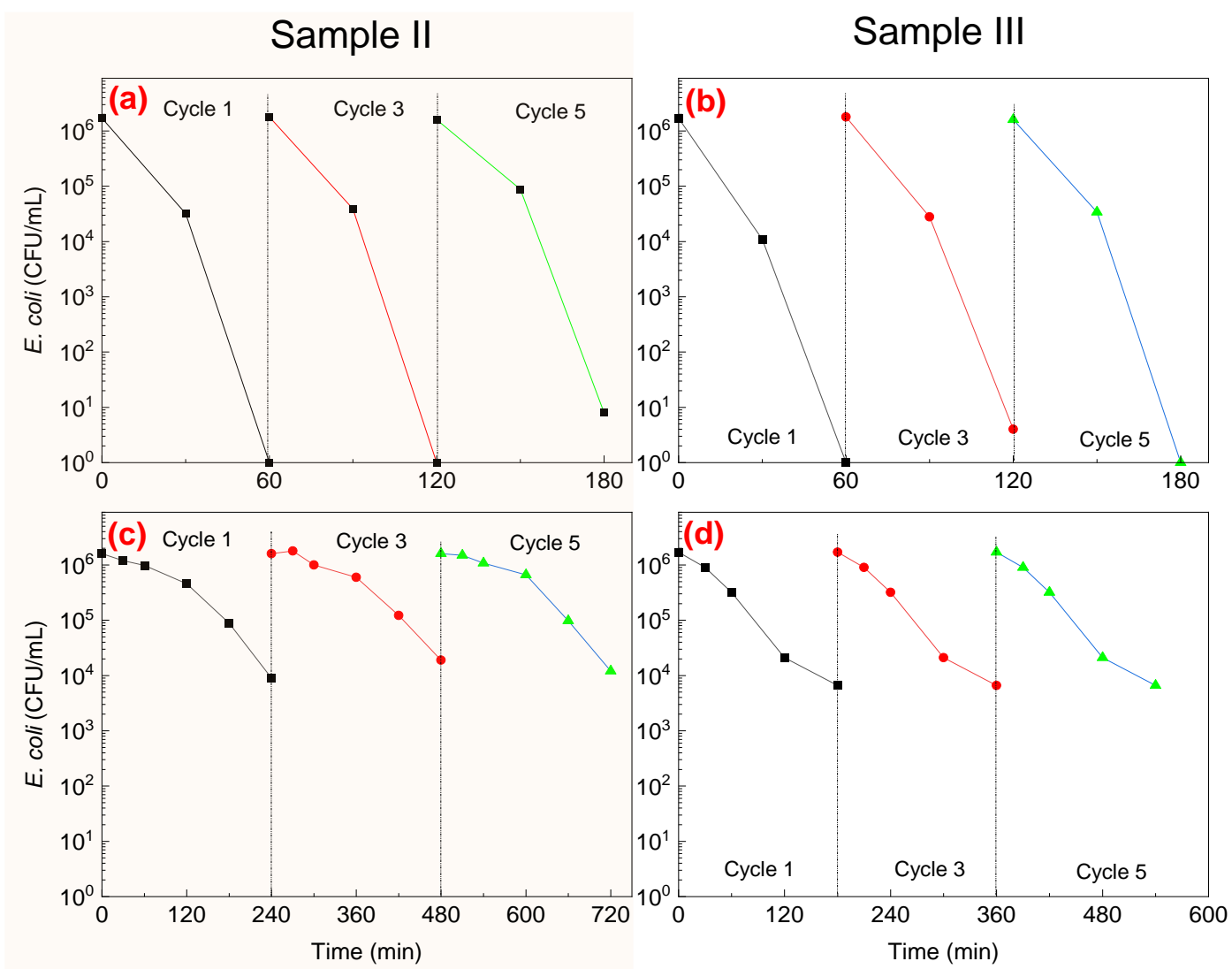

Figure 9. Recycling of E. coli inactivation under light and in the dark on Samples II and III: (a) Sample II under light, (b) Sample III under light, (c) Sample II in the dark, and (d) Sample III in the dark.

The leached copper ions were determined for the as-prepared samples gently washed with water and after the bacterial inactivation cycles. Figure 10 shows the copper ion release from Samples I, II, III, and IV. Sample IV showed the highest copper release. This can be due to the spaced nanocolumns in its microstructure, allowing higher copper amounts to reach the interface with bacteria. This aspect needs deeper investigation. The leached amounts of copper are far below the toxicity threshold. The nanoarchitecture of the prepared coatings allowed the controllable diffusion of copper ions to the interface, with bacteria leading to their inactivation. Detailed Cu-toxicity studies from these coatings are needed when considering the practical application of these films. 


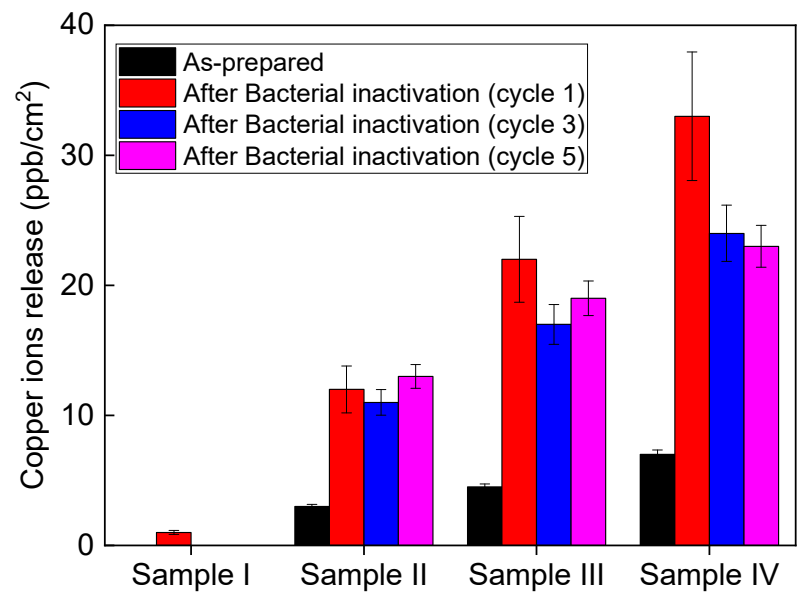

Figure 10. Copper ion release before and after the bacterial inactivation on the different Cu-TNTZ sputtered films.

In our previous study, we showed that TNTZ by itself presents a moderate bacterial inactivation activity [18]. This was attributed to the oxidation of the TNTZ species at the interface, forming oxides able to absorb light and produce reactive oxygen species. Then, we studied the beneficial effect of cosputtering TNTZ with copper/copper oxides, leading to fast bacterial inactivation. This preparation showed fast bacterial inactivation due to the copper species at the interface with bacteria. The preparation led to uncontrollable copper release. In the present study, the copper release seems to be stable over the bacterial inactivation cycles, which reduce the risks of copper toxicity. Figure 11 illustrates the possible mechanism behind the catalytic/photocatalytic activities at the interface of the sputtered nanostructured coatings, especially Sample II, leading to the most controllable copper release.

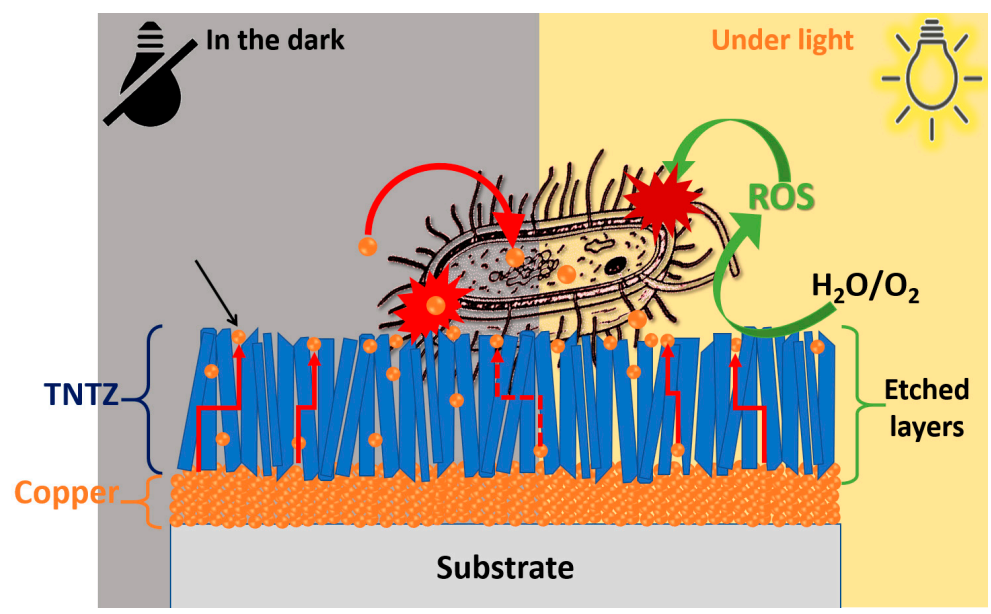

Figure 11. Schematic antibacterial activity at the interface of nanoarchitectured $\mathrm{Cu}-\mathrm{TNTZ}$ thin films prepared by magnetron sputtering.

\section{Conclusions}

Super-elastic titanium-based TNTZ thin films were deposited by DC magnetron sputtering (DCMS) under different working pressures in the range of 0.15-2 Pa. An intermediate dense layer of pure copper was first deposited at a constant pressure of $0.15 \mathrm{~Pa}$. The morphology, microstructure, and surface topography of these samples were studied. The working pressure in the deposition chamber influenced the morphology of the films, which were dense at $0.15 \mathrm{~Pa}$ (low pressure), and columnar architectures were achieved as the pressure values varied from 0.5 to $2 \mathrm{~Pa}$. Bacterial inactivation was seen to happen within 60 min under light for Samples II and III, showing copper ion release. The XPS 
depth profiling of the sputtered bilayers revealed the existence of some copper species in the bulk of the TNTZ upper layer, justifying its diffusion to the surface. Recycling was seen to happen with a stable fashion. The prepared coatings present potential application for indoor environmental prevention, smart surfaces, and biomedical tools (screens, incubators, and other glass-made surfaces able to harbor pathogens).

Supplementary Materials: The following are available online at http://www.mdpi.com/2079-6412/10/6/574/s1, Figure S1: SEM images of TNTZ coatings sputtered at different working pressures.

Author Contributions: Conceptualization, A.A. and S.R.; methodology, A.A., S.A., R.D., and S.R.; validation, A.A. and S.R.; formal analysis, A.A. and S.R.; investigation, A.A., S.A., R.D., and S.R.; data curation, A.A. and S.R.; writing-original draft preparation, A.A. and S.R.; writing-review and editing, A.A. and S.R. All authors discussed the results and implications and commented on the manuscript at all stages. All authors have read and agreed to the published version of the manuscript.

Funding: This research received no external funding.

Acknowledgments: S. Rtimi thanks H. Hofmann (IMX-EPFL) for the samples' characterization.

Conflicts of Interest: The authors declare no conflict of interest.

\section{References}

1. Kim, H.Y.; Sasaki, T.; Okutsu, K.; Kim, J.I.; Inamura, T.; Hosoda, H.; Miyazaki, S. Texture and shape memory behavior of Ti-22Nb-6Ta alloy. Acta Mater. 2006, 54, 423-433. [CrossRef]

2. Tane, M.; Akita, S.; Nakano, T.; Hagihara, K.; Umakoshi, Y.; Niinomi, M.; Nakajima, H. Peculiar elastic behavior of Ti-Nb-Ta-Zr single crystals. Acta Mater. 2008, 56, 2856-2863. [CrossRef]

3. Hu, Q.M.; Li, S.J.; Hao, Y.L.; Yang, R.; Johansson, B.; Vitos, L. Phase stability and elastic modulus of Ti alloys containing $\mathrm{Nb}, \mathrm{Zr}$, and/or Sn from first-principles calculations. Appl. Phys. Lett. 2008, 93, 121902. [CrossRef]

4. Li, S.J.; Cui, T.C.; Hao, Y.L.; Yang, R. Fatigue properties of a metastable $\beta$-type titanium alloy with reversible phase transformation. Acta Biomater. 2008, 4, 305-317. [CrossRef]

5. Sikka, S.K.; Vohra, Y.K.; Chidambaram, R. Omega phase in materials. Prog. Mater. Sci. 1982, 27, 245-310. [CrossRef]

6. Niinomi, M. Fatigue performance and cyto-toxicity of low rigidity titanium alloy, Ti-29Nb-13Ta-4.6 Zr. Biomaterials 2003, 24, 2673-2683. [CrossRef]

7. Laheurte, P.; Prima, F.; Eberhardt, A.; Gloriant, T.; Wary, M.; Patoor, E. Mechanical properties of low modulus $\beta$ titanium alloys designed from the electronic approach. J. Mech. Behav. Biomed. Mater. 2010, 3, 565-573. [CrossRef]

8. Saito, T.; Furuta, T.; Hwang, J.H.; Kuramoto, S.; Nishino, K.; Suzuki, N. Multifunctional alloys obtained via a dislocation-free plastic deformation mechanism. Science 2003, 300, 464. [CrossRef]

9. Otsuka, K.; Ren, X. Recent developments in the research of shape memory alloys. Intermetallics 1999, 7, 511. [CrossRef]

10. Rtimi, S.; Giannakis, S.; Sanjines, R.; Pulgarin, C.; Bensimon, M.; Kiwi, J. Insight on the photocatalytic bacterial inactivation by co-sputtered $\mathrm{TiO}_{2}-\mathrm{Cu}$ in aerobic and anaerobic conditions. Appl. Catal. B Environ. 2016, 182, 277-285. [CrossRef]

11. Baghriche, O.; Rtimi, S.; Pulgarin, C.; Sanjines, R.; Kiwi, J. Effect of the spectral properties of $\mathrm{TiO}_{2}, \mathrm{Cu}$, $\mathrm{TiO}_{2} / \mathrm{Cu}$ sputtered films on the bacterial inactivation under low intensity actinic light. J. Photochem. Photobiol. A Chem. 2013, 251, 50-56. [CrossRef]

12. Wojcieszak, D.; Mazur, M.; Kaczmarek, D.; Szponar, B.; Grobelny, M.; Kalisz, M.; Pelczarska, A.; Szczygiel, I.; Poniedzialek, A.; Osekowska, M. Structural and surface properties of semitransparent and antibacterial $(\mathrm{Cu}$, $\mathrm{Ti}, \mathrm{Nb})$ Ox coating. Appl. Surf. Sci. 2016, 380, 159-164. [CrossRef]

13. Brown, R.D.; Boggs, J.E.; Hilderbrandt, R.; Lim, K.; Mills, I.M.; Niktin, E.; Palmer, M.H. Gum Metal thin films obtained by magnetron sputtering of a Ti-Nb-Zr-Ta target. Mater. Sci. Eng. A 2016, 673, 492-502.

14. Achache, S.; Lamri, S.; Arab Pour Yazdi, M.; Billard, A.; François, M.; Sanchette, F. Ni-free superelastic binary Ti-Nb coatings obtained by DC magnetron co-sputtering. Surf. Coat. Technol. 2015, 275, 283-288. [CrossRef] 
15. Achache, S.; Alhussein, A.; Guelorget, B.; Salut, R.; François, M.; Sanchette, F. Effect of oxygen addition on microstructure and mechanical properties of quaternary TNTZ superelastic thin films obtained by magnetron sputtering. Mater. Chem. Phys. 2018, 217, 262-269. [CrossRef]

16. Achache, S.; Alhussein, A.; Lamri, S.; François, M.; Sanchette, F.; Pulgarin, C.; Kiwi, J.; Rtimi, S. Sputtered Gum metal thin films showing bacterial inactivation and biocompatibility. Colloids Surf. B Biointerfaces 2016, 146, 687-691. [CrossRef] [PubMed]

17. Kanagesan, M.; Hashim, S.; Tamilselvan, A.; Ismail, I.; Ahsanul, K. Synthesis, characterization, and cytotoxicity of iron oxide nanoparticles. Adv. Mat. Sci. Eng. 2013, 2013, 710432. [CrossRef]

18. Alhussein, A.; Achache, S.; Deturche, R.; Sanchette, F.; Pulgarin, C.; Kiwi, J.; Rtimi, S. Beneficial effect of $\mathrm{Cu}$ on Ti-Nb-Ta-Zr sputtered uniform/adhesive gum films accelerating bacterial inactivation under indoor visible light. Colloids Surf. B Biointerfaces 2017, 152, 152-158. [CrossRef]

19. Seddiki, O.; Harnagea, C.; Levesque, I.; Mantovani, D.; Rosei, F. Evidence ofantibacterial activity on titanium surfaces through nanotextures. Appl. Surf. Sci. 2014, 308, 275-284. [CrossRef]

20. Kadlec, R.; Jakubec, M.; Jaglic, Z. A novel flotation technique for the separation of Non-Adherent microorganisms from a substrate. Lett. Appl. Microbiol. 2014, 58, 604-609. [CrossRef]

21. Cullity, B.D. Elements of X-Ray Diffraction, 2nd ed.; Addison-Wesley: Reading, MA, USA, 1978; p. 292.

22. Bonnefond, A.; Gonzalez, E.; Asua, J.M.; Leiza, J.R.; Kiwi, J.; Pulgarin, C.; Rtimi, S. New evidence for hybrid acrylic/TiO2 films inducing bacterial inactivation under low intensity simulated sunlight. Colloids Surf. B Biointerfaces 2015, 135, 1-7. [CrossRef] [PubMed]

23. Lamari, F.; Chakroun, I.; Rtimi, S. Assessment of the correlation among antibiotic resistance, adherence to abiotic and biotic surfaces, invasion and cytotoxicity of Pseudomonas aeruginosa isolated from diseased gilthead sea bream. Colloids Surf. B Biointerfaces 2017, 158, 229-236. [CrossRef] [PubMed]

24. Rtimi, S.; Kiwi, J. Recent advances on sputtered films with $\mathrm{Cu}$ in ppm concentrations leading to an acceleration of the bacterial inactivation. Catal. Today 2020, 340, 347-362. [CrossRef]

25. Rtimi, S. Indoor light enhanced photocatalytic Ultra-Thin films on flexible Non-Heat resistant substrates reducing bacterial infection risks. Catalysts 2017, 7, 57. [CrossRef]

26. Rtimi, S.; Sanjines, R.; Pulgarin, C.; Kiwi, J. Microstructure of Cu-Ag uniform nanoparticulate films on polyurethane 3D catheters: Surface properties. ACS Appl. Mater. Interfaces 2015, 8, 56-63. [CrossRef]

27. Graf, A.; Finkel, J.; Chauvet, A.A.P.; Rtimi, S. Deciphering the mechanisms of bacterial inactivation on HiPIMS Sputtered CuxO-FeOx-PET Surfaces: From light absorption to catalytic bacterial death. ACS Appl. Mater. Interfaces 2019, 11, 45319-45329. [CrossRef]

28. Rtimi, S.; Dionysiou, D.D.; Pillai, S.C.; Kiwi, J. Advances in bacterial inactivation by Ag, Cu, Cu-Ag coated surfaces \& medical devices. Appl. Catal. B Environ. 2019, 240, 291-318.

29. Zeghioud, H.; Assadi, A.A.; Khellaf, N.; Djelal, H.; Amrane, A.; Rtimi, S. Photocatalytic performance of $\mathrm{CuxO} / \mathrm{TiO} 2$ deposited by HiPIMS on polyester under visible light LEDs: Oxidants, ions effect, and reactive oxygen species investigation. Materials 2019, 12, 412. [CrossRef]

(C) 2020 by the authors. Licensee MDPI, Basel, Switzerland. This article is an open access article distributed under the terms and conditions of the Creative Commons Attribution (CC BY) license (http://creativecommons.org/licenses/by/4.0/). 